\title{
Dialogia
}

\section{Livros e leituras para os pequenos leitores: os livros literários e a proto-literatura}

\author{
Books and readings for toddlers: literature books and the proto-literature
}

Cássia Maria Rita Vianna Bittens

Mestra em Literatura e Crítica Literária, pela Pontifícia Universidade Católica de São Paulo cassia.bittens@gmail.com

Diana Navas

Doutora em Letras = Literatura Portuguesa pela Universidade de São Paulo Docente do Programa de Estudos Pós-Graduados em Literatura e Crítica Literária da Pontifícia Universidade Católica de São Paulo, São Paulo, SP - Brasil diana.navas@hotmail.com

\begin{abstract}
Resumo: O presente artigo tem por objetivo estabelecer a diferenciação entre livros literários para primeiríssima e os livros proto-literários, a fim de ampliar as possibilidades de mediação de leitura com crianças pequenas. Para tanto, introduzimos o percurso do desenvolvimento cognitivo infantil auxiliadas pelas teorias da neurociência propostos pelo departamento de estudos da Criança da Universidade de Harvard e pelo modelo do aparelho de pensar propostos pelo pediatra e psicanalista Bernard Golse e Donald Winnicott. Em seguida, apresentamos modelos de mediação de leitura no Brasil e no exterior e, por fim, os critérios para seleção do livro endereçado preferencialmente à primeiríssima infância, bem como a importância do elemento lúdico no literário e no processo de formação do leitor, embasadas no conceito de Homo Ludens proposto por Johan Huizinga.
\end{abstract}

Palavras-chave: Literatura. Crianças pequenas. Proto-literatura. Primeiríssima infância. Lúdico.

\begin{abstract}
The purpose of this article is to differentiate literary books for the very first time and protoliterary books in order to increase the possibilities of reading mediation with young children. To achieve this goal, we introduced the course of child cognitive development aided by the neuroscience theories proposed by the Harvard University Department of Child Studies and by the model of thinking apparatus proposed by the pediatrician and psychoanalyst Bernard Golse and Donald Winnicott. In the sequence, we present models of reading mediation in Brazil and abroad, and finally, the criteria for selecting the book addressed primarily to early childhood, as well as the importance of the ludic element in the literary and in the process of reader formation, based on the concept of Homo Ludens proposed by Johan Huizinga.
\end{abstract}

Keywords: Literature. Toddlers. Proto-literature. First childhood. Ludic. 


\section{Literatura para bebês: uma recente discussão}

Possibilitar o encontro da arte literária com crianças que ainda não leem, historicamente, é uma junção contemporânea, já que a concepção que temos hoje de criança e infância é um fenômeno recente. Segundo Ariès (1981), foi a partir do século XIX que as famílias “adotaram” suas crianças como membros familiares - nesse mesmo período, foi também aberto o primeiro Jardim da Infância na Alemanha, instituição que rapidamente se espalhou pela Europa. Outro fato relevante é a produção de brinquedos. Benjamin (1996) afirma que, com a Revolução Industrial, criou-se a indústria do brinquedo, o que marcou o olhar para a criança como, de fato, criança e potencial consumidora. Assim, é a partir de um fenômeno social e econômico que o infante passa a ser foco de interesse das Ciências Médicas e Humanas.

No início do século XX, na área da Neurociência, o médico e cientista Sigmund Freud desenvolveu a teoria do funcionamento do aparelho psíquico, de acordo com a qual a experiência nos primeiros anos de vida é elementar à saúde mental do indivíduo. $\mathrm{Na}$ área da Pedagogia, Maria Montessori e Emília Ferrero trouxeram ênfase aos processos de desenvolvimento humano, proporcionando grande avanço na concepção de criança pequena. No entanto, foi no período pósguerra que se deu o marco do olhar para o bebê. Os avanços científico-tecnológicos advindos desse momento histórico revolucionaram as Ciências e, especialmente, o surgimento do aparelho de ultrassonografia obstétrica, na década de 1970, proporcionou o acesso ao feto - fator que ampliou a concepção do entendimento da criança. Hoje, estudos comprovam que o bebê a partir do sexto mês em gestação apresenta atividade mental, ainda que rudimentar. É nos primeiros três anos de vida que o bebê alicerça a base de sustentação de sua capacidade de aprender.

Atualmente, no Brasil, o feto em gestação e a criança desde o seu nascimento têm seus direitos assegurados pelo Estado ${ }^{1}$, sendo considerados indivíduos em formação, ou seja, a infância é um período de estruturação do cidadão de maneira global. Também, a garantia à educação na primeira infância, prevista na Lei de Diretrizes e Bases, de 1996, vem promovendo políticas públicas direcionadas à primeira infância. Dentro desse contexto, é natural se pensar na Literatura para aqueles que ainda não leem como experiência possível.

$\mathrm{Na}$ Europa Ocidental, berço das grandes descobertas citadas anteriormente, há mais de trinta anos se investiga a relação livros, leitura e bebês. Bonaffé (2016), pioneira na França em oferecer leituras frequentes aos bebês pelo programa da ACCES (Actions Culturelles Contre les 
Exclusions et les Ségrégations), afirma que as crianças pequenas são sensíveis à melodia dos sons, às cores e aos primeiros contos e rimas, acrescentando ainda que os pais sempre se surpreendem positivamente com as reações dos bebês durante a leitura. O BookStart, na Inglaterra, é um programa governamental que, desde a década de 1980, promove a leitura para bebês em bibliotecas públicas, além de incentivar pais a lerem com os seus filhos desde o nascimento, incluindo, no que eles chamam "bolsa da maternidade", livros e orientações de leitura.

No Brasil, o grande propulsor do olhar para a literatura para bebês foi o Programa Nacional Biblioteca da Escola (PNBE), iniciado em 2008. Bibliotecas das creches de todo o país receberam um grande acervo de livros destinados à primeira infância, inaugurando o debate a respeito da mediação de leitura para bebês no âmbito escolar, bem como sobre os livros para a primeiríssima infância. Assim, nesse recente percurso nacional de apenas uma década, promovido pela área da Educação, o diálogo literatura-bebês vem ganhando espaço na academia e, gradualmente, construindo saberes sobre o tema. Nesse contexto, à área das Letras, precisamente à Crítica Literária, vem sendo solicitada a ampliação dos estudos referentes ao Literário na primeiríssima infância.

\section{$2 \mathrm{O}$ processo formativo do bebê e a literatura}

Para que possamos compreender melhor os livros preferencialmente endereçados aos bebês e a sua mediação de leitura, faz-se necessário entender a concepção de bebê e, ainda que brevemente, seu processo de formação, nos níveis físico, cognitivo e emocional.

Bebês humanos nascem programados para aprender. Já no parto, eles aprendem a respirar pelos pulmões, a chorar e, em pouquíssimos dias, a se alimentar e a se comunicar. O contato intensivo com seu corpo e com o ambiente traz experiências constantes que os constituem como seres pensantes, principalmente até a aquisição do andar estável, que ocorre até os vinte e quatro meses $^{2}$, e o controle dos esfíncteres. Não é coincidência que a "fala" se desenvolva após essas conquistas, afinal, a autonomia vem dos sentidos vivenciados no corpo para o pensar, ou seja, o ser humano, a princípio, é puro sentir, e caminha pela infância rumo ao universo simbólico-metafórico.

O desenvolvimento do corpo é o principal indicador, a olho nu, deste percurso. No quadro abaixo (Fig. 1), podemos observar a evolução da proporção corporal do indivíduo. Aos dois meses fetal, metade do seu tamanho corresponde à cabeça; já aos dois anos, apenas a 25\% do corpo. 
Figura 1 - Mudanças nas proporções do segundo mês fetal à idade adulta

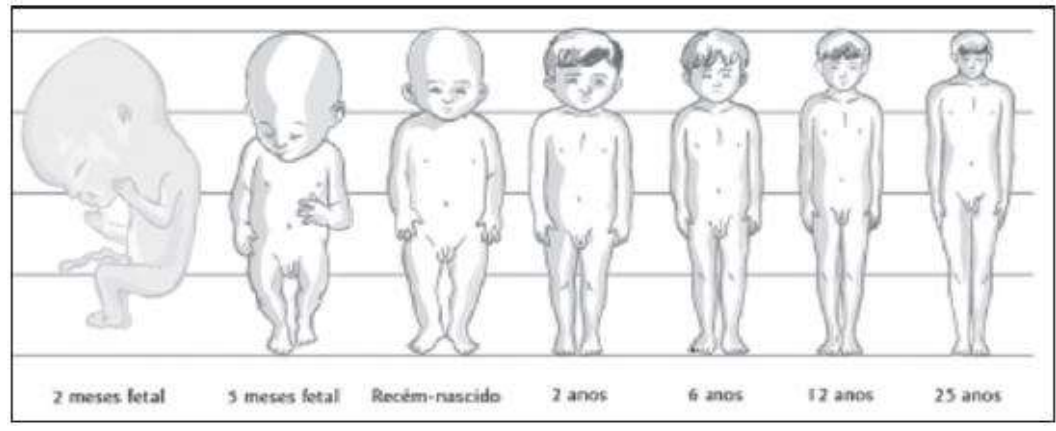

Fonte: (AQUINO, 2011, p. 16).

A atividade cerebral nos primeiros anos de vida é intensa e estrutural. Segundo o HCDC (Center on the Developing Child, Harvard University) (2008), é somente neste período, por meio das sinapses, que são feitas mais de um milhão de novas conexões neuronais por segundo. A arquitetura cerebral, ou o modo como o cérebro se desenvolve, está relacionada à capacidade de criar essa rede e estabelecer contatos entre suas áreas cerebrais, formando uma estrutura sólida e permanente que sustentará aquisições posteriores como, por exemplo, a capacidade de se comunicar e pensar autonomamente. $\mathrm{Na}$ imagem abaixo (Fig. 2), podemos localizar essa rede do desenvolvimento cerebral, que estabelece comunicação entre visão, emoção, habilidades motoras, comportamento, linguagem e memória. Por seu turno, na Fig. 3, notamos a incidência da formação de sinapses em cada mês/idade e, na Fig. 4, a área correspondente à formação de sinapses.

Figura 2 - Arquitetura do cérebro

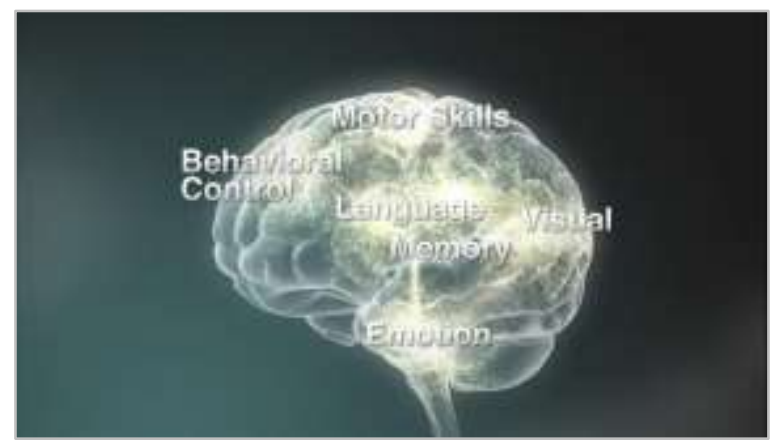

Fonte: HCDC, 2015. 
Figura 3 - Número de sinapses ao longo do tempo: recém-nascido; 1 mês; 9 meses; 2 anos; adulto

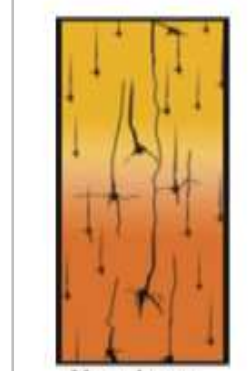

Newborn

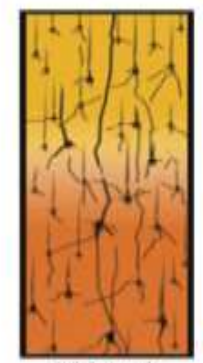

1 Month

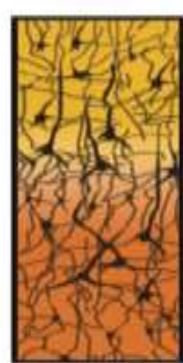

9 Months

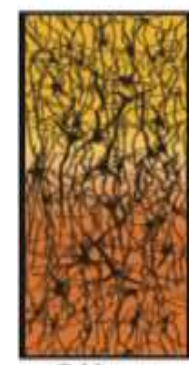

2 Years

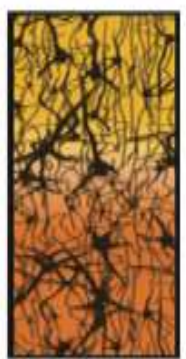

Adult

Fonte: Urban Child Institute (2014, p. 7).

Figura 4 - Formação de novas sinapses

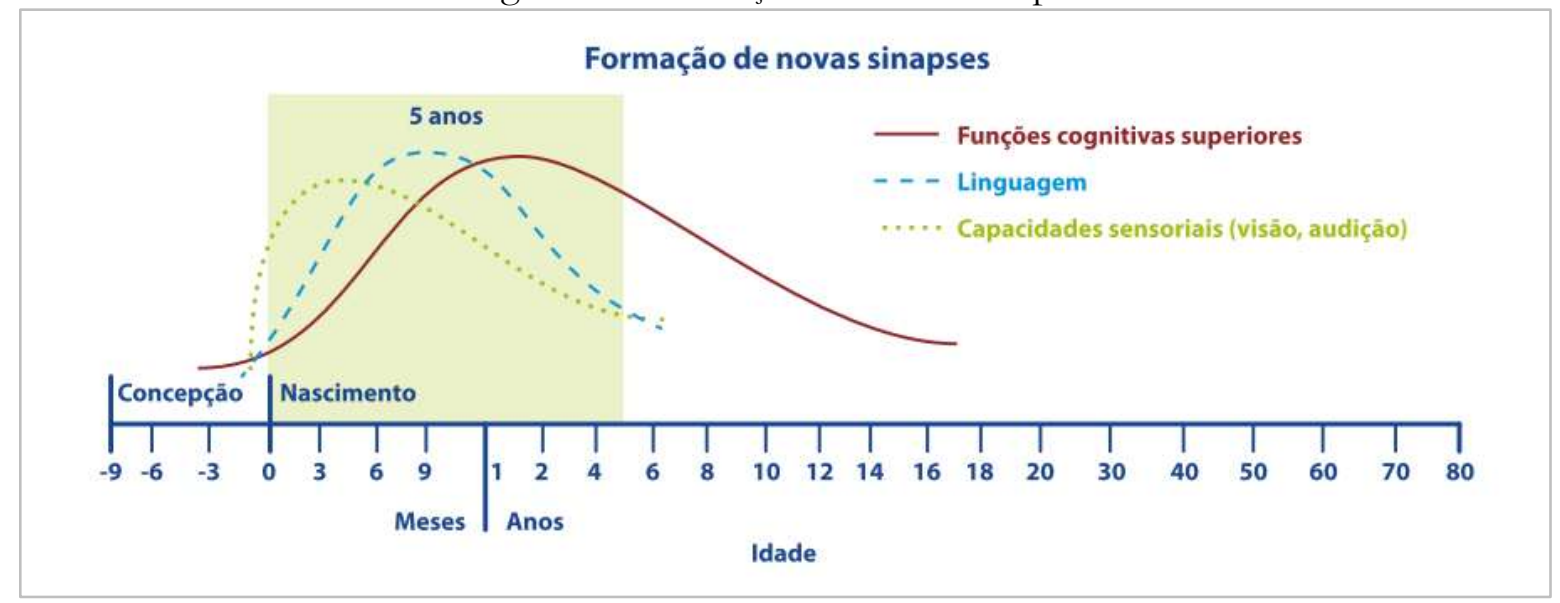

Fonte: Sociedade Brasileira de Pediatria (2015, p.10).

A formação de sinapses nas áreas das capacidades sensórias tem seu ápice nos três primeiros meses de vida; a linguagem, aos nove meses; posteriormente, a atenção se volta às funções cognitivas superiores, em especial o pensar, a função simbólica e a fala, embora tenha seu início três meses antes do nascimento.

Esse crescimento exponencial, inerente à primeiríssima infância, legitimiza o encontro com as primeiras formas de literatura conectadas às primeiras experiências da vida emocional e de pensamento, via corpo e gesto do bebê.

O psiquiatra de bebês e psicanalista Bernard Golse, na obra Do corpo ao pensamento (2002), propõe processos precoces de simbolização e afirma que

o corpo que arrasta sempre atrás de si - quer queira, quer não -, em cortejo de escândalos, mas que - e é essa nossa tese - funciona para a criança como uma passagem obrigatória para os seus sistemas de simbolização e de significação (2002, p. 107).

Ou seja, a capacidade de simbolização está presente desde a tenra idade e, portanto, o corpo é o início dos processos simbólicos no ser humano. Com esta afirmação, excluímos a natureza 
particularmente instintiva (sem pensamento) nos dois primeiros anos da criança para hipotetizarmos que, nesse período, há uma capacidade de representação autônoma. Golse afirma ainda que as competências precoces do bebê apresentadas nos estudos atuais nos fazem considerar, no desenvolvimento da criança, os níveis infraverbais de comunicação e o impacto da intersubjetividade. O autor traz os conceitos de dupla ancoragem corporal e interativa para explicar os processos precoces de simbolização. A ancoragem corporal é a afirmação de que o pensamento se organiza primeiro e, acima de tudo, nas sensações - ao nível do corpo - e, progressivamente, essas sensações terão que ascender ao estado de percepções. A ancoragem interativa, por seu turno, "sublinha a necessidade do desvio pelo outro, necessário à criança para dar, progressivamente, forma e sentido às sensações destinadas a se tornarem percepções” (GOLSE, 2002, p. 104).

Nesse contexto, o autor introduz os "significantes primordiais", ou os primeiríssimos elementos de significação, presos ao corpo, que constituem pares contrastantes, como, por exemplo: mole/duro; redondo/pontiagudo; cheio/oco. Similarmente, esses elementos demarcam profundidade, delimitam o rosto humano e seus contornos etc. Após a identificação deste primeiro aglomerado de significações, os quais foram possíveis em face à interação do parceiro e suas próprias sensações a esta intervenção, o bebê "vai ter então de assumir todo um difícil trabalho de representação dos vínculos primitivos e das primeiras junções, em ligação, por exemplo, com a amamentação (junção boca-mamilo)" (GOLSE, 2002, p. 106). Golse sugere ainda que, com o amadurecimento do processo de simbolização, o bebê evoca, por seu corpo e gestualidade, a ausência do outro (função materna), hipotetizando, por conseguinte, que a imagem motora é, em si, o pensamento e a atividade representativa.

Neste ponto, pensamos a relevância do objeto livro, bem como a materialidade do texto, nas obras endereçadas à primeiríssima infância. Ora, se o pensar segue o fluxo do corpo à mente, este também não seria o início da formação leitora literária?

Como constatamos no pensamento golseniano, a subjetividade - que no início da vida é intersubjetividade - está presente desde os primeiros dias de vida. Assim, as relações estabelecidas consigo mesmo e com seu par exercem papel fundante na constituição do eu. Isto é, o "eu" existe concomitantemente com a espécie humana, porém depende de um outro para vir a ser.

Considerando-se (e delimitando) a linguagem como o ato humano de comunicar algo a si e/ou ao outro, e que carrega a possibilidade de afetar e ser afetado, identificamos no corpo do bebê, desde tenra idade, os primeiros sinais de participação.

Golse (2002), e mais detalhadamente Desjardins e Golse (2005), sugerem dois tipos de comunicação: a comunicação analógica e a comunicação digital. A primeira seria a transmissão não verbal, ou os elementos supra-segmentários da linguagem: tons, ritmos, timbre, entonação etc. E a 
segunda, a comunicação que, por meio de um comportamento linguístico, transmite verbalmente uma mensagem. Esses tipos de comunicação não são antagônicos ou excludentes, pelo contrário - exercem profunda relação no sistema linguístico. Nas palavras dos autores,

\begin{abstract}
Há, na realidade, uma concatenação cerrada entre esses dois tipos de comunicação, e que cada uma delas pode servir conjuntamente aos propósitos metonímicos e metafóricos [...] e, principalmente, que há do analógico no digital - se podemos ousar nos expressar assim -, isto é, que existe uma parte não-verbal do próprio verbal, que é a música da linguagem (DESJARDINS; GOLSE, 2005, p. 17).
\end{abstract}

Importante ressaltar que a comunicação analógica (pré-verbal) antecede a comunicação digital, sendo sua via de entrada. A música da linguagem e os sons (que ouve e que produz) parecem sensibilizar mais o bebê e despertar seu interesse do que a decodificação do código linguístico: "Para entrar na ordem da linguagem (e do simbólico verbal) o bebê precisa - não saber -, mas experimentar e sentir profundamente que a linguagem do outro (e singularmente a de sua mãe) o toca e o afeta, e que esta é afetada e tocada, por sua vez, pelas primeiras emissões vocais dele" (DESJARDINS; GOLSE, 2005, p. 18). Esse afetar - ser afetado e afetar ao outro - consiste em estabelecer uma comunicação profunda com outrem, emitindo sons e gestos, e obtendo a resposta do outro. Não à toa, as brincadeiras com as partes do corpo são espontâneas neste período do desenvolvimento, a ponto de encontrarmos, como nas sugestões de Ramos e Silva (2014), livros para bebês de 0 a 6 meses contendo partes do corpo e do rosto, ou seja, o movimento do seu próprio corpo é fundamental ao desenvolvimento da linguagem. Não pela motricidade em si, mas pelo contato com o outro que o gesto do bebê evoca. Nessa conjuntura, Golse afirma:

E assim, para se tornar "locutor de sua língua", isto é, para dominar progressivamente os seus aspectos pragmáticos, sintáticos e semânticos, a criança não vai entrar logo no código linguístico, mas vai, através do seu corpo e do seu comportamento relacional, descobrir o prazer do "diálogo" com outrem e o prazer de criar sentido (2002, p. 110).

Notamos que, na relação, o bebê é, e que, encontrando guarida, tende a evoluir autonomamente. Ao lançar luz sobre essa possibilidade do "prazer de criar sentido", Golse nos leva a entender que esta é também uma condição da Literatura e, nesse aspecto, talvez tenhamos encontrado uma pista sobre como pensar o literário na primeiríssima infância.

Como exemplo podemos citar cantiga. Fui morar numa casinha.

\title{
Fui morar numa casinha
}

Fui morar numa casinha nhá nhá

Infestada da de cumpim pim pim

Saiu de lá lá lá Uma lagartixa xa

Que olhou pra mim

Que olhou pra mim e fez assim: Brbrbr

(Canção do folclore brasileiro) 
Esta cantiga, que é parte da nossa cultura, traz elementos que caracterizam o literário para crianças pequenas. São eles: a brevidade das frases e da cantiga, a repetição, um conjunto de palavras que ampliam o repertório do bebê e a identificação bebê - lagartixa. O "brbrbr" gesticulado com os lábios, é a lagartixa mas é o bebê que está aprendendo a falar, possibilitando a criança pequena experienciar a narrativa de forma lúdica. Nesse contexto, o brincar é peça fundamental na experiência da Infância, transitando entre individuação - sociedade - saber. Assim, hipotetizamos que o prazer em criar sentido é, também, lúdico.

\title{
3 O lúdico e a formação do leitor literário
}

Por meio do conceito de Homo Ludens, o historiador Huizinga, em 1938, afirma ser o jogo um elemento comum da cultura animal e humana. Em suas palavras:

\begin{abstract}
Em época mais otimista que a atual, nossa espécie recebeu a designação de Homo sapiens. Com o passar do tempo, acabamos por compreender que, afinal de contas, não somos tão racionais quanto a ingenuidade e o culto da razão do século XVIII nos fizeram supor, e passou a ser de moda designar nossa espécie Homo faber. Embora faber não seja uma definição do ser humano tão inadequada como sapiens, ela é, contudo, ainda menos apropriada do que esta, visto poder servir para designar grande número de animais. Mas existe uma terceira função, que se verifica tanto na vida humana, quanto na animal, e é tão importante como o raciocínio e o fabrico de objetos: o jogo. Creio que, depois de Homo faber e talvez ao mesmo nível Homo sapiens, a expressão Homo ludens merece um lugar em nossa nomenclatura (HUIZINGA, 2004, p. 1).
\end{abstract}

Desta forma, teríamos o jogo como fenômeno cultural, atuando efetivamente na vida cotidiana, desde o nascimento. Neste curso de pensamento, o autor afirma que "ser livre" é a primeira característica fundamental do jogo, pois ele próprio é a liberdade. Uma segunda característica é a suspensão da vida real para uma atividade com orientação própria. Nesse momento, o jogo absorve o jogador, criando um tempo outro, "lança sobre nós um feitiço: 'é fascinante', 'cativante'. Está cheio das duas qualidades mais nobres que somos capazes de ver nas coisas: o ritmo e a harmonia" (HUIZINGA, 2004, p. 13). Assim, o elemento lúdico é parte do jogo, sendo este espaço no tempo, limiar entre o jogar ${ }^{3}$ e a realidade.

Neste tema e considerando que os pressupostos de Huizinga são fundamentados na Antropologia e na História, corrobora com este pensar o pediatra e psicanalista Donald Winnicott. O autor, em sua obra O brincar e a realidade (1975), traz o conceito de espaço potencial. O espaço potencial é uma área que não pertence à realidade interna nem à realidade externa do indivíduo, em semelhança ao lúdico proposto por Huizinga. Nas palavras de Winnicott (1975, p. 163): 
Tentei chamar a atenção para a importância, tanto na teoria quanto na prática, de uma terceira área, a da brincadeira, que se expande no viver criativo e em toda a vida cultural do homem. Essa terceira área foi contrastada com a realidade psíquica interna, ou pessoal, e com o mundo real em que o indivíduo vive, que pode ser objetivamente percebido. Localizei essa importante área da experiência no espaço potencial existente entre o indivíduo e o meio ambiente, aquilo que, de início, tanto une quanto separa o bebê e a mãe, quando o amor desta, demonstrado ou tornando-se manifesto como fidedignidade humana, na verdade fornece ao bebê sentimento de confiança no fator ambiental.

O espaço potencial origina-se nas primeiras relações bebê-mãe, tendo sua importância na possibilidade da experiência do brincar e, consequentemente, o viver criativo em sociedade.

Assim, se a ludicidade é um componente do desenvolvimento, podemos pressupor que o livro, enquanto materialidade de um objeto, acolhe texto e imagem por essa ludicidade. Nesse sentido, o papel do adulto leitor assume um papel fundamental ao acesso do bebê ao literário.

A aproximação entre o livro e a criança pequena tende a ser realizada pela mediação desse encontro, ou seja, os livros, num primeiro momento, são necessariamente apresentados e lidos para e/ou com os bebês. Um encontro com graduações, interações e intenções tão amplas que tornam a "mediação da leitura" uma prática realizada sob a ótica de diversos conceitos. Dessa forma, podemos sintetizar que, no Brasil, a mediação da leitura com crianças pequenas ocorre tanto no ambiente educacional (creches) quanto no ambiente sociocultural (bibliotecas, centro culturais e livrarias), assim como no ambiente familiar (pais, avós, irmãos mais velhos, tios, amigos próximos etc.). Desse modo, temos três contextos específicos, os quais pressupõem três mediadores: o professor, o agente cultural (bibliotecário e/ou narrador de histórias) e o adulto familiar - todos aptos a ler.

A mediação da leitura para e/ou com bebês é abordada por autores em diferentes tempos e olhares, tendo como ponto em comum o livro e o conhecimento profundo da obra "mediada"; revelam-se, porém, díspares no tocante à mediação em si. Junqueira (2016), especialista em mediação de leituras na primeiríssima infância no Brasil, principalmente no ambiente escolar, apresenta técnicas de mediação de leitura para crianças pequenas, tendo como princípio a performance da voz e, dependendo da história, a materialização dessa - como, por exemplo, a história de um cachorro na qual, como desfecho, um cachorro de pelúcia é apresentado às crianças. Também sugere que a narrativa, que permite tal contextualização, deve ter pausas e abrir espaço ao mediador para fazer perguntas ou comentários, ampliando as camadas de leituras do enredo. Em relação a essa condução, a autora afirma:

Percebe-se, assim, que ao optar por eleger uma ou outra forma de conduzir o acesso mediante a narratividade vocal - às riquezas e encantos da arte literária, enfocando a proferição e/ou da leitura em voz alta, o professor/leitor/mediador da infância contribui prioritariamente para a formação dos pequenos, não só da escuta narrativa, mas, também, ainda que de maneira indireta, do aprendizado e do desenvolvimento dos modos, gestos e ações embrionários do ato de ler, como prática histórica, discursiva e culturalmente constituída (JUNQUEIRA, 2016, p. 16). 
Junqueira enfatiza a ampla contribuição que a leitura literária propicia à infância, em razão das mediações de leitura realizadas por educadores, bibliotecários e pais, dentro da perspectiva apresentada. Esse modelo, que pela sua natureza lúdica convida à participação e à interação das crianças pequenas, aguçando a investigação e o jogo em torno do literário, parece, no entanto, limitar a espontaneidade e possíveis fruições, tão caras à Literatura de bebê.

A iniciação aos livros infantis e a pré-literacia (ou "literacia emergente"), também é objeto do estudo de Ramos e Silva (2014), que desenvolveram notória pesquisa em Portugal acerca do incentivo à leitura e à formação de leitores na primeira infância.

No tocante às creches, as autoras sinalizam a necessidade de um ambiente alfabetizador rico, compreendendo que a intervenção/interpretação na hora da contação, por parte do mediador, deverá ser contida e ponderada sob pena de quebrar a sequência narrativa ou fragmentar de forma irremediável a interpretação. Nas bibliotecas, por seu turno, as autoras avaliam que a finalidade é o entretenimento, a manipulação dos livros e a mediação da leitura em voz alta, dando especial atenção aos jogos de palavras. Um outro ponto relevante abordado pelas estudiosas é o incentivo aos familiares na mediação da leitura em suas residências.

No ambiente familiar, as autoras portuguesas destacam que os primeiros contatos com os livros contribuem para a formação de leitores autônomos, e sugerem que o bebê deva ser apresentado aos materiais escritos diversos, em encontros que sejam permeados pelo prazer da leitura em família, criando uma rotina de bem-estar e afetos em torno dos livros: "De algum modo, a ideia é que as motivações externas de leituras (a atenção dos adultos, a situação de jogo, os reforços afetivos dos pais), passem a motivações internas (o prazer de ler), colaborando na construção de leitores autônomos" (RAMOS; SILVA, 2014, p. 151). As autoras também afirmam que o ato de ouvir histórias com frequência propicia, ainda, uma experiência em relação aos textos narrativos e às estruturas da língua, possibilitando associações entre o oral e o escrito, entre o grafema e o fonema, fator que extrapola o prazer de simplesmente ouvir uma história. Conforme concluem: "A descoberta dos valores simbólicos da linguagem e as características estéticas que resultam da sua utilização em contexto literário são outras mais-valia associadas a estes momentos" (idem). Neste ponto, voltamos ao lúdico e ao espaço potencial proposto por Winnicott.

Ramos e Silva (2014), portanto, distinguem três formas de mediação possíveis, considerando o ambiente e a finalidade para tal, traçando um caminho intermediário que tende a equilibrar o papel da educação, da sociedade e da família no incentivo à leitura desde o berço.

Considerando nossa experiência prática ${ }^{4}$, as reflexões das pesquisadoras portuguesas corroboram o nosso entendimento de mediação de leitura para bebês, que prioriza o encontro entre o livro de qualidade e sua diversidade com a criança pequena, encontro no qual a importância 
central é atribuída à obra, não à performance do mediador, independente da finalidade e do ambiente da mediação de leitura.

Bonaffé (2016), que desde os anos de 1980 promove leitura para bebês pelo programa francês ACCES 5 , majoritariamente em bibliotecas, enfatiza a importância de "ler por nada" com bebês, e afirma que estes primeiros encontros com as palavras devem ter a intenção do prazer da leitura, sem o desejo da busca de um benefício imediato. Também propõe que, em um grupo, cada criança, dentro das opções do acervo, escolha o que ela quer ler, indicando a leitura individual, onde cada criança espera a sua vez para a leitura literária. A autora enfatiza o cuidado no momento de se intervir na história com perguntas, principalmente nos livros de adivinhação. Em suas palavras: "Em este caso le estamos robando la liberdad em la interpretación de um libro, de uma imagen, de uma historia, así como el placer de hacer é mismo las preguntas"6 (BONAFFÉ, 2016, 1. 1565). Dessa forma, com uma proposta moldada no texto, Bonaffé legitimiza a criança pequena como autora do seu processo de tornar-se leitora pelo ouvir. Esta posição autêntica confirma a importância de se pensar a Literatura de bebês a partir de como o livro pode contribuir para que a criança pequena, por ela mesma, tenha acesso a ele (livro), uma vez que a mediação da leitura está pautada no conhecimento profundo da obra.

Sanjuán afirma que a voz é o primeiro livro do bebê: "Somos el primer libro del bebé y ellos apasionados lectores. Sus reacciones ante la voz literária van desde la atención absorta a la encarnación (el término no es ocioso) del significacdo"”7 (2016, p. 19). Mais adiante, complementa que "el primer espacio qe debemos a la literatura es el que da presencia a la Voz y no a extrañas acumulaciones de datos sobre métrica, géneros e historia literal”8 (SANJUÁN, 2016, p.21). Assim como para Junqueira (2016), citada anteriormente, para Sanjuán a voz é o elemento central na mediação da leitura; porém, as pesquisadoras abordam perspectivas distintas: se, para Junqueira, a voz do mediador é performática (representação), para Sanjuán, a voz é a expressão da cultura humana.

Em nosso entendimento, na mediação de leitura, o bebê deve estar "presente" e ser o ator principal. Considerando um bebê que pensa e é capaz de construir e fruir das pequenas entonações do literário e, dessa forma, enriquecer o seu repertório, podemos hipotetizar que a performance da leitura esteja no corpo do bebê e no objeto livro, e não na voz do mediador. Destarte, a mescla entre apresentar a Literatura e sensibilizar o bebê pelo gesto permite que a criança vivencie a experiência literária.

Se levarmos em consideração os processos de simbolização do bebê, retomando o que foi dito anteriormente por Golse, a ancoragem corporal - as sensações vividas no corpo que progressivamente ascenderão ao estatuto das percepções -, bem como a ancoragem interativa - a 
necessidade que a criança tem da intervenção de um outro para dar forma e sentido às sensações , parece que o papel do mediador vincula-se ao dar forma e sentido à narrativa literária e por à disposição do bebê as primeiras construções da Literatura, sejam elas da tradição oral ou no objeto livro.

Nesse contexto, parece-nos que os livros para mediação da leitura com crianças pequenas assumem duas engrenagens que dependerão da finalidade e sensibilidade do mediador para o momento escolhido da leitura: os livros literários ou os livros "proto-literários". A mediação com livros literários está centrada na figura do mediador: o ritmo, a imagem, todos serão acessados pela perspectiva do adulto e, consequentemente, a aprendizagem literária autônoma estará presente de forma a ser potencializada pelo adulto. Já os livros proto-literários parecem atender à aprendizagem estética, na qual o mediador intervém pontualmente.

Figura 5 - Os livros para primeiríssima infância: duas formas de mediação da leitura com bebês
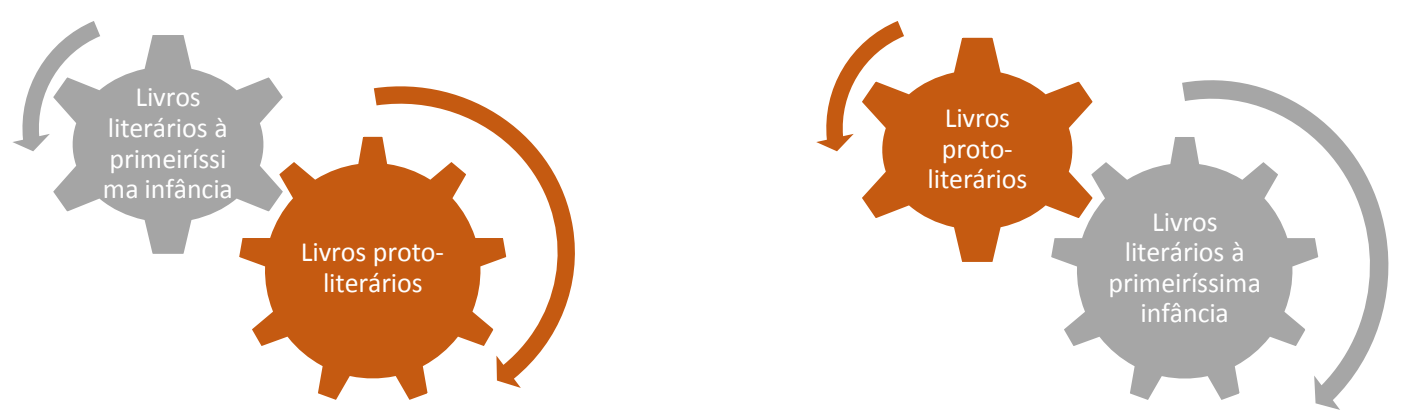

Fonte: (AUTOR 1, 2018).

Os livros literários para primeiríssima infância são aqueles com qualidade literária considerando os seguintes critérios:

a. Ludicidade - O elemento lúdico pela sua qualidade intrínseca, também, à primeiríssima infância, necessariamente estará envolto no objeto-livro como um todo. Assim, o lúdico é uma das portas principais ao literário.

b. Texto - Narrativas breves e melódicas. Como possíveis recursos as onomatopeias, prosopopeias, aliterações, anáforas e polissíndetos.

c. Designer/Materialidade - Os paratextos como elementos à narrativa: capa, guarda, formato, textura, espessura, localização espacial das imagens.

d. Ilustração/Figuras/ Traços - precisos e harmônicos em seu conjunto. Como possíveis recursos, as prosopopeias, ironia e hipérboles. 
Nesse conjunto, temos:

Figura 6 - Critérios norteadores à análise do livro endereçado para a primeiríssima infância

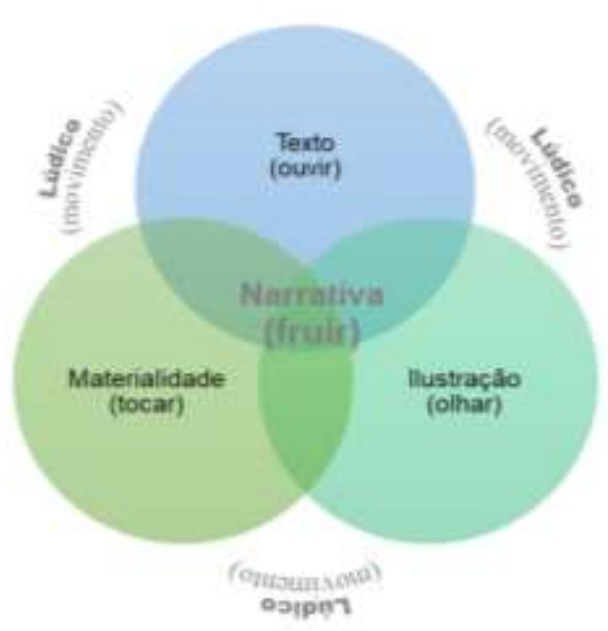

Fonte: (AUTOR 1, 2018).

Ressaltamos que o transitar texto $\leftrightarrow$ materialidade $\longleftrightarrow$ ilustração, permeado pela ludicidade resulta à fruição, premissa basal do literário.

Os livros proto-literários, por seu turno, são aqueles cuja finalidade é trazer os primeiros elementos à aprendizagem estética, possibilitando o pensar autônomo e criativo do bebê. Este é um conceito ainda em desenvolvimento, cujos resultados serão a posteriori aprofundados e apresentados.

A diferenciação entre livros literários endereçados preferencialmente à primeiríssima infância e os livros proto-literários é fundamental ao considerarmos a formação de leitores. A fruição estética é uma emoção individual, porém apreendida e não inata. Equilibrar as potencialidades do bebê enquanto leitor e as nossas ambições na formação literária deste é fundamental para o sucesso do encontro da criança pequena com a Literatura.

1. Brasil, o ECA (Estatuto da Criança e do Adolescente) teve sua criação em 1990, pela LEI 8.069. 2. Segundo o Ministério da Saúde do Brasil (2015, p. 20), entre os dois primeiros anos de vida da criança, deve-se estimulá-la a andar, posteriormente a andar para todas as direções e, em seguida, a chutar.

3. As línguas indo europeias (alemão, inglês, francês) não fazem distinção entre brincar e jogar, já o português faz esta distinção, o que descaracteriza, na nossa língua, o conceito abordado por 
Huizinga, uma vez que, pejorativamente, remetemos o brincar a uma atividade menos complexa ou de menor importância social.

4. Desde 2013, a pesquisadora Cássia V. Bittens promove encontros literários para famílias com bebês de zero a quinze meses em espaços culturais na cidade de São Paulo projeto denominado Literatura de Berço. Disponível em: < http://www.literaturadeberco.com.br>.

5. Actions Culturelles Contre les Exclusions et les Ségrégations (Ações culturais contra os excluídos e segregados).

6. "Neste caso, estamos roubando (do bebê) a liberdade de interpretação de um livro, de uma imagem, de uma história, assim como o prazer de ele mesmo fazer perguntas" (tradução nossa).

7. "Somos o primeiro livro do bebê e eles são leitores apaixonados. As suas reações diante da vOz literária vão desde uma profunda atenção à encarnação (o termo não é ocioso) do significado" (tradução nossa).

8. “o primeiro espaço que devemos à literatura é o que dá presença à Voz e não a estranhas acumulações de dados sobre métricas, gêneros e história literal” (tradução nossa).

\section{Referências}

AGUIAR, Jonathan F. O lúdico é um saber? Vozes docentes sobre lúdico na docência do Ensino Superior. Dissertação (Mestrado em Educação) - Faculdade de Educação, Universidade Federal do Rio de Janeiro/UFRJ, Rio de Janeiro, 2018.

ARIÈS, Phillipe. História social da Criança e da Família. Rio de Janeiro: LTC, 1981.

AQUINO, Leda A. Acompanhamento do crescimento normal. Revista de Pediatria (Suplemento 1), Rio de Janeiro: SOPERJ, v. 12, n. 1, p. 15-20, ago. 2011.

BABY'S Brain Begins Now: Conception to Age 3. In: THE URBAN CHILD INSTITUTE. UCI. s.d. Disponível em: < http://www.urbanchildinstitute.org/why-0-3/baby-and-brain> Acesso em: 07 ago. 2017.

BARTHES, Roland. O praz̧er do texto. São Paulo: Perspectiva, 1987.

BENJAMIN, Walter. História cultural do brinquedo. In: BENJAMIN, Walter. Obras escolbidas vol. 1. Magia e técnica, arte e política: ensaios sobre literatura e história da cultura. São Paulo: Brasiliense, 1996. p. 244-248.

BONAFFÉ, Marie. Ensemble les des temps. Paris: ACCES, 2014.

BONAFFÉ, Marie. Los libros, eso es bueno para los bebês. Ciudad de México: Océano Exprés, 2016. E-Book. ISBN 9786077358671. Disponível em: < http://oceano.mx/obras/los-libros-eso-esbueno-para-los-bebes-marie-bonnafe-14428.aspx > Acesso em:10 jun. 2017. 
BRAIN Architecture. In: CENTER ON THE DEVELOPING CHILD. Harvard University. s.d. Disponível em: < https://developingchild.harvard.edu/science/key-concepts/brainarchitecture/> Acesso em: 07 ago. 2017.

BRASIL. Ministério da Educação. PNBE - Programa Nacional da Biblioteca da Escola. s.d.A

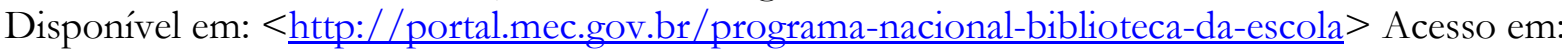
15 set. 2017.

BRASIL. Ministério da Educação. PNLD - Programa Nacional do Livro e do Material Didático. s.d.B Disponível em: < http://portal.mec.gov.br/busca-geral/318-programas-e-acoes1921564125/pnld-439702797/12391-pnld> Acesso em:15 ago. 2018.

BRASIL. Ministério da Educação. PNBE na escola: literatura fora da caixa. Brasília: Ministério da Educação; Secretaria de Educação Básica, 2014. Disponível em:

$<$ http: $/ /$ portal.mec.gov.br/index.php?option $=$ com docman\&view $=$ download\&alias $=15609$ guia-ei-leituraforadacaixa-pdf\&category slug=maio-2014-pdf\&Itemid=30192> Acesso em:15 out. 2017.

BRASIL. Ministério da Saúde. Caderneta de Saúde da Criança - Menina. 10. ed. Brasília: Ministério da Saúde, 2015. Disponível em:

$<\underline{\text { http://bvsms.saude.gov.br/bvs/publicacoes/caderneta saude crianca menina 10ed.pdf }>}$ Acesso em:23 ago. 2017.

CAMPANHA Receite um livro. In: SOCIEDADE BRASILEIRA DE PEDIATRIA. SBP. s.d. Disponível em: < http://www.sbp.com.br/campanhas/campanha/cid/receite-um-livro/> Acesso em:29 ago. 2017.

COELHO, Nelly N. Literatura Infantil: teoria, análise, didática. 5. ed. São Paulo: Ática, 1991.

FROM Best practices to breakthrough impacts. In: CENTER ON THE DEVELOPING CHILD. Harvard University. s.d. Disponível em:

$<$ https://developingchild.harvard.edu/resources/from-best-practices-to-breakthrough-impacts/ $>$ Acesso em: 03 dez. 2018.

GOLSE, Bernard; DESJADINS, Valérie. Corpo, formas, movimentos e ritmo como precursores da emergência da intersubjetividade e da palavra no bebê. Trad. Regina O. de Aragão. Revista Latinoamericana de Psicopatologia Fundamental, São Paulo: AUPPF, v. 8, n. 1, p. 14-29, jan./mar. 2005.

GOLSE, Bernard. Do corpo ao pensamento. Trad. Margarida Cabral Fernandes. Lisboa: CLIMEPSI, 2002.

GUTFREIND, Celso. A infância através do espelho: a criança no adulto, a literatura na psicanálise. Porto Alegre: Artmed, 2014.

HUIZINGA, Johan. Homo Ludens. 5. ed. Trad. João Paulo Monteiro. São Paulo: Perspectiva, 2004.

JUNQUEIRA, Renata. Literatura infantil e primeira infância: políticas e práticas de leitura. FronteiraZ, São Paulo: PUC-SP, n. 17, p. 43-59, 2016. 
KÜMMERLING-MEIBAUER, Bettina (Ed.). Emergent Literacy: Children's books from 0 to 3. Amsterdam: John Benjamins Publishing Company, 2012.

KÜMMERLING-MEIBAUER, Bettina (Ed.). et al. (Eds.). Learning from Picturebooks: Perspectives from child development and literacy studies. New York: Routledge, 2015.

MARTINS, Diana; SILVA, Sara R. Banhos com história(s): contributos para uma caracterização do livro de banho. In: 4th CONFIA - International Conference on Illustration and Animation, 2016, Barcelos. CONFIA 2016. Barcelos: Escola Superior de Design - IPCA, June 2016. p. 6674.

RAMOS, Ana M.; SILVA, Sara R. Leitura do Berço ao Recreio. Estratégias de promoção da leitura com bebês. In: VIANA, Fernanda; RIBEIRO, Iolanda; BAPTISTA, Adriana (Orgs.). Ler para ser: os caminhos antes, durante e... depois de aprender a ler. Coimbra: Edições Almedina, 2014. p. 149-174.

RAMOS, Ana M. Livros de Palmo e Meio: reflexões sobre Literatura para a Infância. Lisboa: Caminho, 2007.

REYES, Yolanda. A Casa Imaginária. São Paulo: Global Editora, 2010.

SANJUÁN, Beatriz. Érase una voz: El primer libro del bebé. Zaragoza: Pantalia, 2016.

WINNICOTT, Donald W. O brincar e a realidade. Trad. José O. A. Abreu e Vanede Nobre. Rio de Janeiro: Imago, 1975.

Recebido em: 03 dez. 2018 / Aprovado em: 25 jun. 2019

\section{Cite como}

BITTENS, Cássia Maria Rita Vianna; NAVAS, Diana. Livros e leituras para os pequenos leitores: os livros literários e a proto-literatura. Dialogia, São Paulo, n. 32, p. 222-265, maio/ago. 2019. Disponível em: https://doi.org/10.5585/Dialogia.n32.11019. 